\title{
“Cuál es el plan?” Sobre la interpretación y la metainterpretación en Legalidad de Scott Shapiro*
}

\author{
"What's the Plan?" \\ On Interpretation and Meta-interpretation \\ in Scott Shapiro's Legalidad
}

Giorgio Pino**

Recepción y evaluación de propuesta: 24/10/2017

Aceptación: 26/02/2018

Recepción y aceptación final: 16/08/2018

Resumen: E1 libro de Scott Shapiro, Legalidad, es una contribución realmente rica e innovadora dentro de la filosofía analítica del derecho. El objetivo de este trabajo es explicar y evaluar la teoría de la interpretación de Shapiro, tal como resulta presentada en Legalidad, una parte importante de la empresa teórica de Shapiro que todavía no ha atraído, por lo que yo sé, mucho interés en la ya conspicua literatura sobre este libro. Más específicamente, en lo que sigue intentaré ofrecer a) una reconstrucción de la teoría de la interpretación jurídica de Shapiro, tal como se encuentra desarrollada en Legalidad; b) un análisis de esa teoría en sus propios términos (es decir, su coherencia interna, su carácter persuasivo general); y c) una evaluación de la compatibilidad entre esa teoría de la interpretación jurídica y el proyecto más general del "derecho como plan".

Palabras clave: interpretación, metainterpretación, teoría del derecho como plan.

* Traducción de Federico José Arena.

** Università di Roma Tre, Roma, Italia. E-mail: giorgio.pino@uniroma3.it 
Giorgio Pino

\begin{abstract}
Scott Shapiro's book, Legalidad, is a very rich and challenging contribution to analytical legal philosophy. The aim of this essay is to explain and evaluate Shapiro's theory of legal interpretation, as outlined in Legalidad - an important part of Shapiro's theoretical enterprise that has not yet attracted, as far as I know, much interest in the already conspicuous literature on this book. More specifically, I will try to provide $a$ ) a reconstruction of Shapiro's theory of legal interpretation, as it is developed in Legalidad; $b$ ) an assessment of this theory of interpretation on its own terms (i.e. its internal coherence, its overall persuasiveness) and c) an evaluation of the compatibility of this theory of legal interpretation with the general project of "Law as Plan".
\end{abstract}

Keywords: interpretation, meta-interpretation, planning theory of law.

\title{
I. Introducción
}

E1 libro de Scott Shapiro, Legalidad, es una contribución realmente rica e innovadora dentro de la filosofía analítica del derecho, o, como diría Shapiro, dentro de la analytical jurisprudence ${ }^{1}$. El libro, aun cuando sea extenso y rico de referencias históricas y teóricas (ambas ciertamente útiles para reforzar el argumento central del libro), posee una estructura claramente lineal. Abraza una tesis fundamental acerca de la naturaleza del derecho ("la teoría del derecho como plan"), que es desarrollada de manera detallada y articulada, defendida coherentemente frente a los posibles rivales, y aplicada a numerosas (es más, todas las) facetas del fenómeno analizado, es decir, el derecho.

En definitiva, la empresa de Shapiro consiste en ofrecernos, dentro de la tradición del positivismo jurídico, una teoría bien desarrollada del derecho. En este sentido, Neil MacCormick nos señala que "una teoría del razonamiento jurídico exige, y es exigida por, una teoría del derecho" ${ }^{2}$. El punto es, en efecto, bastante claro. Toda teoría de la interpretación jurídica presupone una teoría del derecho, es decir, una teoría acerca del objeto de la interpretación jurídica misma. Pero a su vez,

1 Véase Shapiro, S., Legalidad, Madrid-Barcelona, Marcial Pons, 2014, pp. 26-27, sobre la distinción entre filosofía del derecho "normativa" y "analítica".

2 MacCormick, N., Legal Reasoning and Legal Theory, Oxford, Clarendon, 1978, p. 229. 
“¿Cuál es el plan?”. Sobre la interpretación y la metainterpretación...

y de manera igualmente importante, una teoría del derecho quedaría incompleta si no desarrollara las consecuencias que su adopción acarrea respecto de cuestiones interpretativas. Una teoría del derecho que no posea consecuencias respecto de cuestiones de interpretación y, al revés, una teoría de la interpretación que pueda ser asociada a cualquier teoría del derecho son, si bien no inconcebibles, altamente sospechosas.

El objetivo de este trabajo es explicar y evaluar la teoría de la interpretación de Shapiro, tal como resulta presentada en Legalidad.

Más específicamente, en lo que sigue intentaré ofrecer (a) una reconstrucción de la teoría de la interpretación jurídica de Shapiro ( $\S$ 1); (b) un análisis de esa teoría en sus propios términos (es decir, su coherencia interna, su carácter persuasivo general, etc.) (§ 2); (c) una evaluación de la compatibilidad entre esa teoría de la interpretación jurídica y el proyecto más general del "derecho como plan" (§ 3). Por "compatibilidad" no me refiero a la mera consistencia lógica, sino más bien a su "solidez". En otras palabras, la exigencia de solidez en la construcción de teorías exige que una teoría de la interpretación no sea construida de manera tal que frustre los objetivos de la teoría del derecho a la cual está asociada ${ }^{3}$.

\section{II.La teoría de los planes: de la teoría del derecho a la teoría de la interpretación}

Aproximadamente la mitad de Legalidad (capítulos VIII-XIII) está dedicada a problemas de (teoría de la) interpretación. En otras palabras, Shapiro es perfectamente consciente del hecho que las cuestiones relativas a la interpretación son vitales para el proyecto del derecho como plan. Me referiré entonces, brevemente, a la teoría de la interpretación jurídica delineada en conexión con el derecho como plan.

3 Puesto que creo que una teoría del derecho y una teoría de la interpretación "van de la mano", en una suerte de equilibrio reflexivo, el contrario también vale; es decir, si lo que se desea es construir una teoría más o menos plausible, una teoría del derecho no debería volver irrelevantes las cuestiones de interpretación. 
La primera cosa que, quizás, ha de notarse es que el derecho como plan no es solo una teoría positivista, sino una teoría positivista fuerte. De hecho, la teoría de los planes (o el derecho como plan, o "positivismo acerca de los planes" ${ }^{\prime 4}$ es explícitamente una reformulación del positivismo jurídico excluyente o fuerte ${ }^{5}$, a partir de algunas herramientas teóricas nuevas como, principalmente, el concepto de "plan". No me referiré aquí en detalle al sofisticado esquema teórico de Shapiro, me limitaré a señalar simplemente los siguientes elementos:

- Un plan es un tipo de norma ${ }^{6}$ : un plan es una guía para el comportamiento (selecciona cursos de acción que son exigidos, permitidos o autorizados bajo ciertas circunstancias) y es un estándar para la evaluación del comportamiento (se supone que sea usado para medir la corrección de un comportamiento). De todos modos, no es necesario que discipline completamente y de manera instantánea el tipo de comportamiento al que se aplica; un plan puede ser "parcial". Incluso más, un plan es una entidad "intencional positiva" (positive purposive), es decir "una norma es un plan en tanto fue creada por un proceso que se supone que debe crear normas" 7 haga que los sujetos a los que se dirige estén dispuestos a seguirla ${ }^{8}$.

- La razón por la cual recurrimos a los planes es que reducen los costos de deliberación en circunstancias de incertidumbre. Se trata de circunstancias en las que los agentes enfrentan la complejidad, la conflictividad y la arbitrariedad de la vida en común, como consecuencia de desacuerdos morales sustanciales, de incertidumbre acerca de cuál es el modo más efectivo de alcanzar fines valiosos, etc.

- El derecho (en el sentido de "sistema jurídico") es una organización planificadora: una organización que lleva a cabo una actividad de

4 Esta denominación aparece en Shapiro, S., op. cit., p. 225.

Ibidem, pp. 328-335.

6 Ibidem, pp. 169-171.

7 Ibidem, p. 170.

8 Ibidem, p. 171: "un plan es una clase especial de norma. En primer lugar, tiene una estructura característica, a saber, es parcial compuesta y anidada. En segundo lugar, es creada por un cierto tipo de proceso, a saber, uno incremental, intencional y que dispone a los destinatarios a cumplir con las normas creadas". 
“¿Cuál es el plan?”. Sobre la interpretación y la metainterpretación...

planificación, i. e. que produce planes. La exigencia de adoptar un plan jurídico es consecuencia de las "circunstancias de la legalidad". Estas últimas "se producen cuando una comunidad afronta muchos y serios problemas cuyas soluciones son complejas, controvertidas o arbitrarias" 9 .

- Cuando se lo compara con otras organizaciones planificadoras (tales como las organizaciones criminales, por ejemplo), el derecho se caracteriza por un fin particular, a saber, "rectificar las deficiencias morales asociadas con la circunstancias de la legalidad"10 ("tesis del fin moral"). Esta es, según Shapiro, la función fundamental del derecho.

Dado que (a) la actividad jurídica es una actividad de planificación; (b) una actividad de planificación consiste en hacer (diseñar, desarrollar, e implementar) planes; y (c) los planes son normas; es obvio concluir que los planes producidos por la actividad jurídica son normas jurídicas y, a la inversa, que las normas jurídicas son planes (o, al menos, "similares a los planes" en aquellos casos en que no sean creadas positivamente por una organización de planificación, sino adoptadas por ellas) ${ }^{11}$.

Asimismo, la actividad jurídica es una actividad de planificación no solo porque produce planes (normas), sino también porque ella misma se encuentra estructurada como un plan ${ }^{12}$. Mediante esta expresión, Shapiro quiere decir que en la base de la actividad de planificación jurídica (producción, modificación y aplicación de normas jurídicas) se encuentra el "plan maestro". Este plan regula las actividades de planificación adicionales que han de ser llevadas a cabo por los fun-

9 Ibidem, p. 216.

${ }^{10}$ Ibidem, p. 265. ¿Cómo es posible saber que el derecho posee esa "finalidad moral"? Shapiro afirma que "los funcionarios de alto rango representan la práctica como si tuviese un fin o fines morales"; "la describen como una actividad que se supone que ha de solucionar problemas morales y que debería ser obedecida por esa razón": pp. 269-270. Parece entonces que la principal razón, para afirmar que esa finalidad moral constituye la función fundamental del derecho, es que los funcionarios actúan, por así decirlo, como si el derecho efectivamente poseyera esa finalidad moral.

11 Ibidem, p. 161.

12 Ibidem, p. 224. 
cionarios, establece las divisiones de trabajo institucional entre ellos (la formulación y la adopción de nuevos planes, su aplicación, etc. $)^{13}$. En la mayoría de los sistemas jurídicos, el plan maestro puede ser convencionalmente identificado con la Constitución ${ }^{14}$, aun cuando parte (o la totalidad) del plan maestro pueda también ser de naturaleza consuetudinaria, y por lo tanto solo similar a los planes. Este conjunto de reglas fundamentales (el plan maestro) existe porque se trata de un "plan compartido"15.

Luego de efectuadas estas pocas anotaciones acerca del esquema general de la teoría de los planes, me referiré con mayor atención al papel que en ella tiene la interpretación jurídica ${ }^{16}$.

La interpretación es la actividad mediante la cual se da un significado a un texto jurídico. Todo acto de interpretación puede, por lo tanto, ser subsumido bajo una determinada "metodología interpretativa", es decir, "un método para interpretar los textos jurídicos"17.

Toda cultura jurídica admite una amplia variedad de métodos interpretativos (por ejemplo, la interpretación literal, la interpretación intencionalista, la interpretación histórica, la interpretación teleológica, etc.). Además, para cualquier caso (a) el intérprete tiene legítimamente a disposición más de un método interpretativo, y (b) los diferentes métodos interpretativos disponibles pueden conducir a resultados interpretativos distintos. Se sigue de ello que el intérprete, en la mayoría de los casos (quizás siempre), debe elegir entre numerosos

13 Ibidem, pp. 224-227.

14 Ibidem, pp. 215, 256.

15 Ibidem, p. 224: "un plan social solo existe si fue diseñado con un grupo en mente, de manera que puedan participar en una actividad conjunta, es públicamente accesible y es aceptado por la mayoría de los miembros del grupo en cuestión. Como resultado, si se desea descubrir la existencia o el contenido de las reglas fundamentales de un sistema jurídico, debemos observar exclusivamente estos hechos sociales".

${ }^{16}$ La teoría de la interpretación pertenece al ámbito de las "preguntas de la implicación". En cambio, no pertenece a la definición del derecho, tampoco a lo que hace que el derecho sea lo que es (la "pregunta de la identidad"), sino que se sigue de ella. Véase ibidem, p. 404: "para saber cómo interpretar el derecho debemos responder la Pregunta de la Implicación"; véase también pp. 33-36, sobre la distinción entre "preguntas de identidad" y "preguntas de implicación".

17 Ibidem, p. 369. 
“¿Cuál es el plan?”. Sobre la interpretación y la metainterpretación...

métodos interpretativos disponibles. Esta elección es una cuestión de "metainterpretación", o de una teoría metainterpretativa ${ }^{18}$.

Ahora bien, la primera implicación para la interpretación que posee la teoría de los planes es bastante obvia. Si las normas jurídicas son planes, entonces la interpretación jurídica es interpretación de planes ${ }^{19}$. Recuérdese que un plan es un dispositivo que, "atando las manos" de sus destinatarios, permite reducir los costos de deliberación en situaciones de incertidumbre, complejidad, conflictividad, etc. (las circunstancias de la legalidad). Los destinatarios deberán seguir el plan ciegamente ${ }^{20}$, sin deliberación ulterior ${ }^{21}$. Dado que las normas jurídicas son planes, y los planes han de desempeñar precisamente esta función, se sigue que las normas jurídicas han de ser interpretadas (y deben ser tales como para poder ser interpretadas) de modo tal que no resurjan las mismas cuestiones controvertidas, que el plan estaba destinado a cerrar ${ }^{22}$.

Shapiro se ocupa de estas cuestiones bajo el título "Lógica General de los Planes" (LOGEP). La interpretación, de cada uno de los elementos de un sistema de planes, no puede estar determinada por los mismos hechos que el sistema estaba destinado a decidir ${ }^{23}$.

Por lo tanto, Shapiro prefiere una teoría metainterpretativa que respete LOGEP. Esto exige recurrir al concepto de "confianza". Los sistemas jurídicos son planes, y los planes están basados sobre ciertas

18 Ibidem, pp. 370-371.

${ }^{19}$ Ibidem, pp. 244-245.

20 Por supuesto, existen límites a esto. Un plan no debería ser seguido "pase lo que pase", a cualquier costo. Véase Shapiro sobre la derrotabilidad (ibidem, pp. 252-253, 368): todos los planes vienen de fábrica con una cláusula "a menos que surjan razones de peso".

21 Shapiro denomina esto la "Simple Lógica de los Planes" (SLOP): "la existencia y el contenido de un plan no pueden estar determinados por hechos cuya existencia el plan pretende establecer"; ibidem, p. 337.

22 Ídem ("isería absurdo tener planes para ahorrarnos la deliberación si el modo correcto de descubrir su existencia o contenido nos exigiera llevar a cabo la deliberación!"; ibidem, p. 374 ("el contenido de las normas, en la medida en que son planes, debe poder ser descubierto de modo que no requiera la resolución de cuestiones que se supone debe resolver el derecho"); ibidem, p. 375.

23 Ibidem, p. 377. 
actitudes de confianza ${ }^{24}$. La metainterpretación exigida por la teoría de los planes se concentra así en el modo en que efectivamente se encuentra distribuida la confianza dentro de los sistemas jurídicos. Cualquier plan (como cualquier sistema jurídico) está basado en algún tipo de sistema de administración de la confianza. Si un plan o, más precisamente, los diseñadores del plan confían ampliamente en que un determinado (tipo de) actor será capaz, en un tipo de circunstancia, de enfrentar las circunstancias de la legalidad, entonces el sistema autorizará a ese actor a desarrollar el plan (el plan le dará discreción interpretativa). Si, por el contrario, el sistema asume que un determinado (tipo de) actor, en un tipo de circunstancia dada, no es confiable, o no lo es suficientemente -en otras palabras, si el sistema asume que el actor no será capaz de enfrentar las circunstancias de la legalidadentonces dará a ese actor un papel restringido (deberá limitarse a seguir ciegamente el plan, sin intentar desarrollarlo) ${ }^{25}$.

Esto es lo que Shapiro llama la "economía de la confianza" de un sistema ${ }^{26}$. La economía de la confianza es esencial para la elección de una metodología interpretativa, puesto que la distribución del poder de decisión que implica una metodología interpretativa ha de ser consistente con la economía de la confianza del sistema. Ahora bien, surge una pregunta ciertamente obvia: "¿cómo es posible determinar la economía de la confianza sobre la que efectivamente se basa el sistema?"27. Shapiro estipula dos (familias) de métodos posibles.

El primero es el "método del Ojo de Dios". Este método exige que cada (meta)intérprete decida autónomamente acerca de su propio

24 Ibidem, p. 379 ("los planes son herramientas poderosas para gestionar la confianza y la desconfianza").

25 Ibidem, p. 427.

26 Ibidem, p. 404.

27 En p. 410, Shapiro da por probado que la distribución de las tareas interpretativas, basada en consideraciones de confianza, es un trabajo de los legisladores. En consecuencia, parece que deberíamos primero buscar en las leyes para resolver problemas metainterpretativos. Pero esto es claramente un error, puesto que da por resuelta, sin argumentos, la cuestión relativa al nivel de confianza que ha sido conferido a los legisladores mismos. Claramente, el plan maestro podría conferir, comparativamente, más confianza a los legisladores respecto de determinadas cuestiones, y menos respecto de otras. 
“¿Cuál es el plan?”. Sobre la interpretación y la metainterpretación...

nivel de confianza. Si el intérprete considera que se encuentra en una posición que merece una gran cantidad de confianza (ya sea en todas o solo en algunas circunstancias), se atribuirá discreción interpretativa. $\mathrm{Si}$, por el contrario, él mismo considera que no es confiable, entonces "se atara sus propias manos", y recurrirá al juicio de otra persona.

El segundo es el "método de los Planificadores". En este caso, "un metaintérprete no debería evaluar su propia confiabilidad, sino deferir a las concepciones de los planificadores del sistema con respecto a su competencia y carácter" 28 y, sobre esa base, elegir la metodología interpretativa.

En otras palabras, un intérprete que recurra al método del Ojo de Dios está de hecho fijando la economía de la confianza del sistema. Por el otro lado, un intérprete que recurra al método de los Planificadores intenta sujetarse a la economía de la confianza tal como ha sido determinada por los diseñadores del plan (i.e. los Framers) ${ }^{29}$.

Obviamente, la teoría de los planes exige el "método de los Planificadores" en la metainterpretación y rechaza con firmeza el método del Ojo de Dios. El primer método es claramente consistente con LOGEP, mientras que el último lo viola abiertamente y reabre la caja de Pandora de las circunstancias de la legalidad ${ }^{30}$.

Pero este no es todavía un veredicto definitivo contra el método del Ojo de Dios y en favor del método de los Planificadores. De hecho, la elección entre el método del Ojo de Dios y el método de los Planificadores depende de razones y actitudes que efectivamente poseen los participantes del sistema jurídico.

28 Ibidem, p. 414: "Su tarea es extraer las actitudes de confianza de los planificadores tal y como están recogidas en los planes del sistema jurídico, y luego utilizar esas actitudes para determinar cuánta discreción se debe conceder. La confianza de los planificadores en la competencia y el carácter deberían conllevar importantes niveles de discreción interpretativa; la duda y la sospecha deberían conducir a reducidos niveles de discreción".

${ }^{29}$ Respecto de la afirmación según la cual los diseñadores del plan son quienes han creado la constitución, véase ibidem, p. 421 (véase también infra, § 4).

${ }^{30}$ Ibidem, p. 422. 
Giorgio Pino

En un sistema 'autoritativo', la razón por la que la mayor parte de los funcionarios de justicia acepta, o afirma aceptar, las reglas del sistema es que esas reglas se crearon por quienes tenían una autoridad moral o juicio superior. La procedencia autoritativa de esas reglas, en otras palabras, es considerada de suprema importancia moral. En un sistema 'oportunista', en cambio, los orígenes de la mayor parte de esas reglas son considerados moralmente irrelevantes. Los funcionarios en esos regímenes los aceptan porque reconocen, o dicen reconocer, que esas reglas son moralmente buenas y por tanto promueven el objetivo fundamental del derecho ${ }^{31}$.

Que un sistema jurídico sea del tipo "autoritativo" o del tipo "oportunista" es una cuestión empírica. De hecho, Shapiro cree que el sistema jurídico estadounidense actual pertenece al primer tipo ${ }^{32}$. De todos modos, el método de los Planificadores es apropiado (de hecho, exigido) solo por los sistemas del tipo "autoritativo".

Así, en un sistema del tipo "autoritativo" la economía de la confianza (las actitudes de confianza de los planificadores del sistema ${ }^{33}$ ) será determinada utilizando el método de los Planificadores, que a su vez consiste en una teoría metainterpretativa articulada en tres pasos. “1. Especificación. ¿Qué competencias y carácter se necesitan para implementar los diferentes tipos de procedimientos interpretativos? 2. Extracción. (a) ¿Qué competencia y carácter que creían los planificadores que tenían los actores les llevaron a confiar a los actores la tarea que les encomendaron? (b) ¿Qué objetivos sistémicos pretendían los planificadores que los diversos actores persiguieran y realizaran? 3. Evaluación. ¿Qué procedimiento promueve y realiza mejor los objetivos sistémicos que se suponía que los actores debían promover y realizar, asumiendo que tienen la competencia y el carácter extraídos?"34.

\footnotetext{
31 Ibidem, p. 424.

32 Ibidem, p. 425.

33 Ibidem, p. 418.
}

$346 \quad{ }^{34}$ Ibidem, pp. 433-434. 
“¿Cuál es el plan?”. Sobre la interpretación y la metainterpretación...

Al final de todo esto, y luego de tomar en cuenta también algunas cuestiones relativas a la "competencia" 35 , el metaintérprete se encontrará en una buena posición para identificar la metodología interpretativa apropiada para cualquier clase de intérprete. Todo este proceso, además, está basado únicamente en hechos sociales (los juicios de competencia y de carácter de los planificadores, la ideología que inspira el régimen ${ }^{36}$ ), por lo que el positivismo jurídico se ve aquí reivindicado.

En definitiva, la teoría de la interpretación jurídica desarrollada en Legalidad posee, explícitamente, dos límites. En primer lugar, se aplica únicamente a sistemas jurídicos que poseen ciertas características específicas, es decir, se aplica solo a sistemas autoritativos, tal como han sido definidos más arriba. Segundo, las bases concretas de esta teoría de la interpretación (toda la panoplia de cuestiones metainterpretativas) quedan indeterminadas, puesto que son radicalmente contextuales. Todo depende de cómo un concreto sistema jurídico distribuye cantidades de confianza y desconfianza entre sus funcionarios -i.e., depende de la economía de la confianza del sistema-. Así, si el sistema jurídico considera que una cierta clase de funcionarios es merecedora de confianza, $\mathrm{o}$ comparativamente más confiable que otra clase de funcionarios, entonces otorgará a la primera una cantidad apreciable de discreción interpretativa (permitiéndole usar estilos teleológicos de interpretación, por ejemplo). Si, en cambio, el sistema jurídico desconfía de una cierta clase de funcionarios, o desconfía de ella en comparación con otra clase de funcionarios, entonces exigirá a la primera clase que no use sus poderes interpretativos, y probablemente le exigirá también que adhiera a las

${ }^{35}$ Ibidem, p. 455: "La relación competitiva entre los planificadores sociales es en sí misma un elemento meta-interpretativo crucial. Esto es así porque los planes jurídicos no solo gestionan la confianza; también gestionan el conflicto. Los planes, como se ha señalado anteriormente, son herramientas extremadamente útiles para resolver disputas políticas. Me gustaría ahora sostener que si los planes desempeñan la función de gestionar conflictos, cuanto más competitiva sea la relación de planificación, más restrictiva es la metodología interpretativa; a la inversa, cuanto más colaborativo es el ejercicio de planificación social, más discreción interpretativa se confiere".

36 Ibidem, p. 460. Shapiro ofrece una presentación bastante similar de la tarea del intérprete en "The 'Hart-Dworkin' Debate: A Short Guide for the Perplexed", en Ripstein, A. (ed.), Ronald Dworkin, Cambridge, Cambridge U. P., 2007. 
palabras de las reglas establecidas por los diseñadores del plan (o establecidas por otros funcionarios más confiables).

Por lo que, al final, la teoría del derecho como plan no se ve comprometida con una metodología interpretativa en particular, sino que, en cambio, exige a cada intérprete que elija la metodología interpretativa apropiada, en relación a su papel y el lugar que posee en la economía de la confianza del sistema. Y es precisamente tarea de cada intérprete determinar, siguiendo la ideología que anima al sistema, cuál es su papel y lugar en la economía de la confianza del sistema.

\section{Algunas dificultades de la teoría de los planes}

A partir de este esquema teórico general, y bien complejo, intentaré señalar a continuación algunos puntos críticos del modo en que la reoría de los planes de Shapiro trata algunas cuestiones de interpretación y metainterpretación.

1. ¿Decisión judicial libre de valores? Según la teoría del derecho y de la interpretación de Shapiro, el razonamiento jurídico es necesariamente amoral ${ }^{37}$. Esto significa que, por lo que se refiere al genuino razonamiento jurídico, el intérprete no recurre (y no debe recurrir) a consideraciones morales. El intérprete debe simplemente dirigir su mirada a los hechos sociales (como por ejemplo, las leyes positivas). Por supuesto, Shapiro concede que la solución de una disputa puede exigir que el juez deba "salir del derecho", y corroborar los hechos morales para decidir una disputa. Es más, según Shapiro, esto puede, de hecho, resultar en ocasiones inevitable, dado que el derecho es producto de seres humanos, cuya habilidad para prever todas las disputas relevantes y todas las propiedades relevantes de las disputas posibles es limitada (es decir, la habilidad para planificar de los seres humanos es limitada). Dado que el derecho es un producto humano y dado que los seres humanos poseen tanto limitaciones cognitivas como mora- 
“¿Cuál es el plan?”. Sobre la interpretación y la metainterpretación...

les, el derecho se ve intrínsecamente limitado. Cuando el intérprete se enfrenta a un caso cuya solución (o quizás cuya solución óptima) no es ofrecida por el derecho existente, la decisión del caso ha de ser alcanzada por fuera del derecho. Y en un caso tal, el juez no llevará ya a cabo un razonamiento jurídico (que es necesariamente amoral), sino que se tratará de una pura decisión legal: en ese caso el juez no aplicará derecho existente, sino que decidirá una disputa ${ }^{38}$.

Traduciendo todo esto al vocabulario de la teoría de los planes, en algunos casos (los casos difíciles) el plan original puede "agotarse", y los jueces se verán obligados a escribir por su cuenta un nuevo plan que les permita decidir el caso en cuestión ${ }^{39}$.

Ahora bien, me pregunto si el retrato que la teoría de los planes ofrece de la tarea judicial es iluminador. De hecho, sospecho que en realidad oscurece elementos esenciales del razonamiento jurídico.

Mi principal observación aquí es que todos y cada uno de los actos de interpretación involucran necesariamente un juicio de valor. Esto es cierto, por supuesto, en aquellos casos de indeterminación extrema, de lagunas, de conflictos entre normas en ausencia de criterios claros de solución, de conflictos entre exigencias jurídicas y exigencias morales, etc. (casos difíciles). Pero esto también es cierto en casos en los que existe un texto legal, formulado con palabras claras. Ello es así porque (a) incluso las palabras claras han de ser interpretadas (no llevan consigo un significado adherido en la frente) y poseen zonas de penumbras (un grado relativo de vaguedad e indeterminación es un rasgo ineliminable del lenguaje), e incluso la elección misma de recurrir al significado literal es precisamente eso, una elección; (b) un texto legal dado

38 Ibidem, p. 335: "Entonces, la práctica judicial en el sistema jurídico estadounidense no exige que los positivistas jurídicos abandonen la idea de que el derecho está determinado en última instancia $y$ exclusivamente por hechos sociales. Porque cuando los estándares con pedigrí se agotan, los jueces estadounidenses tienen simplemente la obligación jurídica de ejercer una discreción fuerte, observando la moral más allá del derecho para resolver el caso que les ocupa".

39 Ibidem, p. 339: "El hecho de que, en esos casos, los jueces se basen con frecuencia en consideraciones morales indica simplemente que llevan a cabo una nueva planificación social". 
es claro en tanto y en cuanto no se vea "perturbado", es decir, en tanto y en cuanto no sea puesto en discusión por un caso específico que no encaja de manera perfecta en la formulación del texto legal (¿cuál sería en ese caso la tarea del intérprete?, ¿recurrir a entidades dudosas tales como "el propósito" del plan, incluso cuando el intérprete ha sido considerado no confiable por los diseñadores del plan, o incluso cuando él mismo se considera de ese modo?); (c) en los sistemas basados en el precedente, un caso puede por lo general ser subsumido en más de un precedente; incluso es común inferir más de una ratio decidendi a partir de un único precedente; (d) en los sistemas continentales, el intérprete se enfrenta siempre a una amplia variedad de materiales legales, y no solo a una ley, o a parte de una ley; además, el intérprete debe llevar a cabo un análisis sobre la validez de la norma que ha de ser interpretada, lo que requerirá tareas interpretativas adicionales.

Lo que estoy queriendo señalar mediante las observaciones precedentes es que, con frecuencia, el intérprete enfrenta situaciones en las que debe tomar decisiones sustantivas de varios tipos; no solo en los casos difíciles sino también en los fáciles. Estas decisiones estarán guiadas por consideraciones sustantivas y evaluativas (ideas de razonabilidad, plausibilidad, etc. ${ }^{40}$ ). Si todo esto es correcto, entonces la distinción de Shapiro entre el razonamiento jurídico propiamente entendido (que es necesariamente amoral) y la decisión judicial (que involucra el ejercicio de algún tipo de razonamiento moral por parte de los jueces) es equivocada, puesto que el razonamiento jurídico amoral no se verifica nunca.

Además, si el argumento de arriba es correcto, es necesario llevar a cabo un ajuste significativo de la teoría de los planes. En efecto, puesto que (a) la decisión judicial libre de valoraciones no existe y, (b) el intérprete se ve siempre obligado a agregar algo al plan, entonces (c)

${ }^{40} \mathrm{E}$ denominado argumento $a b$ absurdo (el método interpretativo que prohíbe al intérprete alcanzar resultados absurdos) es un caso paradigmático de ello. Para un buen inventario de casos, incluso más rutinarios, que involucran el ejercicio de razonamiento moral sustantivo por parte de los jueces, véase Waldron, J., "Do Judges Reason Morally?", en G. Huscroft (ed.), Expounding the Constitution. Essays in Constitutional Theory, Cambridge, Cambridge U. P., 2008, pp. 38-64. 
“¿Cuál es el plan?”. Sobre la interpretación y la metainterpretación...

la diferencia entre los diseñadores y los aplicadores del plan colapsa. En el mejor de los casos, esa diferencia es meramente una diferencia de grado $^{41}$. Pero una implicación fuerte (y coherente) del argumento sería que los jueces siempre son diseñadores y no meramente aplicadores del plan. Regresaré sobre este punto más abajo (§ 4).

El argumento relativo a los límites del derecho produce también otra perplejidad. Es cierto, el derecho posee límites, puesto que es una empresa humana, social. Por ello es bastante fácil que, en algunos casos, el "derecho se agote", al menos aparentemente. Pero me parece bastante irreal sostener que, cuando el derecho se agota, el intérprete está legitimado para salirse del derecho y buscar una respuesta en el campo de la moral. De hecho, en la mayor parte de los sistemas jurídicos contemporáneos que conozco, cuando el derecho se ha aparentemente agotado, los intérpretes no buscan directamente una buena solución sobre bases morales; por el contrario, continúan buscando la guía del derecho incluso en los casos difíciles ${ }^{42}$. En otras palabras, el derecho positivo ejerce todavía una especie de "fuerza gravitacional" sobre el razonamiento judicial incluso cuando, en sentido estricto, no controla el caso. Así, el derecho podría exigir al intérprete que decida el caso mediante referencia a principios generales (o constitucionales),

${ }^{41}$ Es bastante famoso el argumento de Hans Kelsen, según el cual la aplicación y la creación del derecho son actividades continuas. "La norma de rango superior no puede determinar en todos los sentidos el acto mediante el cual se aplica. Siempre permanecerá un mayor o menor espacio de juego para la libre discrecionalidad, de suerte que la norma de grada superior tiene, con respecto del acto de su aplicación a través de la producción de normas o de ejecución, el carácter de un marco que debe llenarse mediante ese acto" (Kelsen, H., Teoría pura del derecho, México, UNAM, 1982, p. 350). Según Leslie Green, esta es "una verdad general acerca de las normas" (Green, L., "Legal Positivism", en Stanford Encyclopedia of Philosophy, 2003).

42 Hart, H. L. A., "Postscript", en The Concept of Law (1961), Second Edition. Oxford, Oxford University Press, 1994, p. 274 (58): "cuando las leyes o precedentes particulares se muestran indeterminados o cuando el derecho explícito calla, los jueces no arrojan sus libros de derecho y empiezan a legislar sin ninguna guía del derecho". [N. E.: no se ha consolidado aún una traducción canónica de las notas manuscritas de Hart, que Joseph Raz y Penelope Bulloch incluyeron como "Postscript" en la segunda edición de The Concept of Law (pp. 238-276). A los fines de lograr uniformidad se cita en la traducción de Rolando Tamayo y Salmorán: Hart, H. L. A., Post scríptum 
a la analogía, a los precedentes, etc. Por supuesto, en tales casos, el intérprete deberá mayormente apoyarse en consideraciones valorativas y sustanciales, y la solución puede ser más controvertida que en otros casos (por ejemplo, principios diferentes pueden sustentar analogías o resultados diferentes). Pero de todos modos, ello es meramente una cuestión de grado, puesto que ello también sucede en los casos fáciles, tal como hemos visto.

Asimismo, que los jueces decidan los casos difíciles por fuera del derecho es meramente contingente, una posibilidad específica de cada sistema ${ }^{43}$. Por ejemplo, en un sistema jurídico dado, podría prohibirse a los jueces decidir los casos difíciles, debiendo someterlos a la legislatura. Así, la tesis según la cual en casos difíciles, cuando el derecho (o los planes) se han agotado, los jueces necesariamente deciden por fuera del derecho, debería ser entendida no como una verdad conceptual acerca del derecho, sino como una cuestión contingente, relativa a cada sistema jurídico específico. Esto, a su vez, sería más consistente con el alcance limitado que posee la teoría de los planes en la interpretación jurídica. Como hemos visto (supra, § 2), la teoría de los planes en la interpretación no ofrece respuestas precisas a los problemas interpretativos en general, sino que exige analizar cuidadosamente la economía de la confianza de cada sistema jurídico. Así, un sistema jurídico dado podría administrar los casos difíciles en alguno de los siguientes modos (o incluso algún tipo de combinación de ellos). Primero, podría exigir a los jueces que sí o sí decidan el caso, aun cuando tengan que recurrir a algún tipo de razonamiento moral. Segundo, podría exigir a los jueces que sometan el caso a la decisión de la legislatura o de un tribunal superior o especializado. Tercero, podría incluso exigir a los jueces que se limiten a corroborar que el caso no posee solución en el sistema, y por lo tanto que no exige un pronunciamiento judicial (non liquet). En definitiva, no constituye una verdad conceptual que, en los

al concepto de derecho, México, UNAM, 2000. En paréntesis se indican las páginas correspondientes a la traducción].

43 Ver el artículo de Chiassoni en este mismo número: Chiassoni, P., "Una mirada desde el realismo analítico: vieja metafísica, señoría de los truismos, positivismo sospechoso", Discusiones, XX (2), 2017. 
“¿Cuál es el plan?”. Sobre la interpretación y la metainterpretación...

casos difíciles, los jueces recurran a argumentos morales por fuera del derecho. Los jueces lo harán solo si están obligados a decidir el caso difícil; pero además, también en este supuesto podría mostrarse, en mi opinión, que el derecho positivo es capaz de, en algún modo, ejercer todavía cierto control sobre el razonamiento judicial.

En consecuencia, contra Shapiro, mi conclusión en este punto es que el razonamiento jurídico está siempre contaminado por argumentos morales, tanto en los casos fáciles como en los difíciles, pero que merece de todos modos ser llamado razonamiento jurídico. Podemos decidir llamarlo decisión jurídica si nos apetece, pero entonces debemos reconocer que eso es lo que los jueces hacen todo el tiempo y no solo, ocasionalmente, en los casos difíciles. Además, ¿no es una importante obviedad acerca del derecho, que el trabajo de los jueces es el de aplicar el derecho? Una vez que advertimos que la decisión judicial involucra siempre argumentos valorativos, la tesis de Shapiro, según la cual un razonamiento jurídico "moralmente contaminado" deja de ser un razonamiento jurídico (y se convierte en una decisión judicial por fuera del derecho), no logra explicar esta obviedad.

2. Extraer la economía de la confianza a partir del plan maestro. Según Shapiro, la construcción de la teoría metainterpretativa que demanda la teoría de los planes exige identificar la economía de la confianza incorporada en el sistema ${ }^{44}$. Además, Shapiro sostiene que la existencia y el contenido del plan maestro es una cuestión meramente empírica ${ }^{45}$.

Como hemos visto (supra, $\S 2$ ), este proceso conlleva tres pasos (especificación, extracción, evaluación). Aquí me concentraré brevemente en la etapa de extracción.

La extracción es "esencialmente un proceso explicativo. El meta-intérprete intenta mostrar que la estructura institucional de un sistema particular se debe, en parte, al hecho de que quienes lo diseñaron

44 Shapiro, S., op. cit., p. 433: "una metodología interpretativa es adecuada para un intérprete en un determinado sistema jurídico solo si persigue mejor los objetivos que se confía que los actores alcancen, bajo la presuposición de que los actores tienen la competencia y el carácter que les atribuyen quienes diseñaron el sistema".

45 Ibidem, p. 192. 
tenían ciertas concepciones sobre la confiabilidad de los actores en cuestión y, por tanto, confiaban [sic] a los actores ciertos derechos y responsabilidades. Las concepciones extraídas a partir de esta práctica son aquellas que explican mejor la construcción y la adopción de los textos que guían la práctica". Asimismo, las "concepciones [de los diseñadores] sobre la confiabilidad de los actores son jurídicamente relevantes solo en la medida que desempeñaron un rol causal en el actual diseño y la adopción de textos autoritativos" 46 . Para Shapiro, la extracción no es necesariamente una empresa holista (al estilo Dworkiniano). E1 metaintérprete puede contentarse con determinar únicamente las actitudes de confianza que el sistema muestra hacia él y su papel. Como criterio general, los funcionarios de bajo rango no necesitan embarcarse en una verificación general de las relaciones de confianza del sistema, mientras que puede ser el caso que los funcionarios de alto rango sí deban hacerlo.

El metaintérprete extraerá las actitudes de confianza de los diseñadores a partir de "la estructura del sistema jurídico" 47 o, si lo necesita, a partir de "una indagación histórica más detallada" 48 .

Shapiro es perfectamente consciente de que este no es un trabajo sencillo. Los sistemas jurídicos suelen poseer una larga trayectoria de vida, su diseño suele ser el resultado de contribuciones bien variadas, y pueden incorporar actitudes de confianza diferentes en niveles diferentes (por ejemplo, una norma constitucional puede incorporar cierta actitud de confianza hacia cierto tipo de intérprete, mientras que una ley ordinaria puede incorporar una actitud de confianza diferente respecto de ese mismo tipo de intérprete).

Dado que los sistemas jurídicos se construyen y reconstruyen con el transcurso del tiempo, normalmente de la mano de

46 Ibidem, p. 436.

${ }^{47}$ Ibidem, p. 257: "Cuando los sistemas jurídicos están diseñados para alcanzar ciertas metas morales o políticas, a menudo es posible captar las metas de los sistemas mediante un análisis detallado de sus planes maestros. Por ejemplo, un sistema que prevé votaciones, representación, elecciones y alguna protección de la deliberación pública valora el autogobierno democrático". 
“¿Cuál es el plan?”. Sobre la interpretación y la metainterpretación...

numerosos individuos, sería extremadamente sorprendente encontrar un conjunto coherente de concepciones sobre la confianza subyacente a la totalidad de los textos jurídicos. Como cuestión general, la tarea del meta-intérprete no es simplemente recuperar esas actitudes de confianza dispares sino también sintetizarlas en una concepción racional. Entonces, la economía de confianza de un sistema se construye durante la meta-interpretación, no simplemente se la descubre ${ }^{49}$.

Shapiro describe este proceso como una especie de investigación empirica relativa a hechos sociales ${ }^{50}$. Es sobre esto que, a su vez, se basa la asunción de Shapiro según la cual la teoría del derecho como plan es fuertemente positivista, y sobre lo que también se basa, claramente, la idea misma de concebir el derecho como plan $^{51}$.

Ahora bien, me parece un poco sorprendente que el proceso de extracción pueda plausiblemente ser concebido como una investigación empírica relativa a hechos sociales. Por supuesto, que alguien posea una determinada creencia, o posición ideológica o ética, etc., es ciertamente una cuestión de hecho. Pero cuando se trata de describir o construir el contenido de tales creencias, o posiciones éticas o ideológicas, etc., es bastante extraño concebir eso como una investigación empírica, o factual ${ }^{52}$. En consecuencia, por mi parte, argumentaría que identificar la economía de la confianza de un sistema no es una cuestión puramente (ni tampoco principalmente) empírica. Por el contrario, exige llevar a cabo una investigación sustantiva acerca de los propósitos de los diseñadores, sus actitudes e intenciones, sus ideologías, sus compromisos (puesto que tales ideologías pueden, y suelen, ser diferentes e incompatibles), y cuánto de todo ello se encuentra en el texto de la constitución. Todo ello lleva a que inevitablemente el (meta-)intérprete

${ }^{49}$ Ídem.

50 Ibidem, pp. 338, 460-462.

51 Ibidem, pp. 225: "el intento por descubrir la existencia o el contenido de tal mecanismo [i.e. del plan maestro] atendiendo a la filosofía moral, como recomienda el iusnaturalista, frustraría la función del plan maestro".

52 Raz J., Razón práctica y normas, Madrid, Centro de estudios constitucionales, 1991, p. 20: "las creencias, pero no sus contenidos, son también hechos". 
realice juicios de valor, i. e. juicios sustantivos de plausibilidad, tales como los que exige el "principio de caridad"53. Una vez que el (meta-) intérprete pone sus manos sobre este tipo de cosas, no puede ya pensarse que lleva a cabo una investigación meramente empírica.

Esto resulta particularmente claro, por ejemplo, cuando el (meta-) intérprete enfrenta inconsistencias internas en el plan maestro, i. e. cuando el plan maestro parece apoyarse en juicios de confianza incompatibles. Para resolver estos casos, Shapiro aconseja seguir un procedimiento epistemológico que toma prestado del modo en que la filosofía de la ciencia afronta el problema de las teorías inconsistentes, en particular de W. V. O. Quine ${ }^{54}$-un procedimiento que, desde mi punto de vista, puede ser descrito como una especie de equilibrio reflexivo rawlsiano-.

Nótese que mi objeción no conlleva una toma de posición respecto de la alternativa entre punto de vista externo y punto de vista interno. Quiero decir, lo que está en discusión aquí no es la posibilidad de formular enunciados no comprometidos, en lugar de enunciados comprometidos o evaluativos. En ambos casos (i. e., enunciados evaluati-

53 Un argumento más extenso puede verse en Villa, V., "Legal Theory and Value-Judgements", Law and Philosophy, 16, 1997, pp. 447-477; Celano, B., "Come deve essere la disciplina costituzionale dei diritti?", en Pozzolo, S. (ed.), La legge e i diritti, Torino, Giappichelli, 2002, pp. 89-123; Id., "Giusnaturalismo, positivismo giuridico e pluralismo ético", Materiali per una storia della cultura giuridica, 2005, pp. 161-184. Pueden también mencionarse algunas afirmaciones de Joseph Raz acerca de la teoría hartiana de la regla de reconocimiento: "Tratar de formular criterios de validez basados en las prácticas complejas de los tribunales las cuales cambian constantemente, que son por fuerza vagas y ciertamente casi incompletas, supone no sólo sensibilidad jurídica y conocimiento teórico sino, además, sano juicio y razonables decisiones valorativas. La teoría de Hart conduce a donde la frontera entre teoría jurídica analítica y teoría jurídica crítica, es decir, donde la distinción entre teoría general y teoría particular del derecho, comienza a oscurecerse" (Raz, J., La autoridad del derecho. Ensayos sobre derecho y moral, México, UNAM, 1985, p. 125).

54 Shapiro, S., op. cit., p. 443: "Esta teoría establece varias hipótesis por lo que respecta a la competencia y al carácter general de los individuos y cómo los escenarios particulares afectan su confiabilidad. Cuando una revisión de un sistema jurídico introduce juicios de confianza en conflicto dentro de esta 'teoría', el meta-intérprete debería entonces emprender una revisión mínima: debería sintetizar los juicios previos tan poco como sea posible para hacerlos consistentes". 
“¿Cuál es el plan?”. Sobre la interpretación y la metainterpretación...

vos internos y enunciados evaluativos externos) lo que está en juego es exactamente eso: un enunciado evaluativo, que conlleva el uso de argumentos sustantivos (incluso si, por hipótesis, de modo no comprometido). Un enunciado evaluativo no es un enunciado empírico.

En resumen, mi objeción aquí es que concebir la etapa de extracción de la metainterpretación como una investigación factual o empírica es una deformación, cuya finalidad es ofrecer a los positivistas jurídicos (excluyentes) un retrato tranquilizador del razonamiento jurídico, basado exclusivamente en hechos sociales.

3. ¿El alcance de la teoría de los planes es demasiado estrecho? Los argumentos que he presentado hasta aquí se refieren a problemas de consistencia interna de la teoría metainterpretativa de Shapiro. A continuación quisiera formular un argumento crítico desde una perspectiva ligeramente distinta. La teoría metainterpretativa de Shapiro está basada en la asunción de que el sistema jurídico bajo análisis posee ciertas propiedades, a saber, que se trata de un "sistema autoritativo", por oposición a un "sistema oportunista".

Recuérdese que

en un sistema 'autoritativo', la razón por la que la mayor parte de los funcionarios de justicia acepta, o afirma aceptar, las reglas del sistema es que esas reglas se crearon por quienes tenían una autoridad moral o juicio superior. La procedencia autoritativa de esas reglas en otras palabras, es considerada de suprema importancia moral. En un sistema 'oportunista', en cambio, los orígenes de la mayor parte de esas reglas son considerados moralmente irrelevantes. Los funcionarios en esos regímenes los aceptan porque reconocen, o dicen reconocer, que esas reglas son moralmente buenas y por tanto promueven el objetivo fundamental del derecho ${ }^{55}$.

Únicamente en un "sistema autoritativo" funciona el método de los Planificadores. Ahora bien, que un sistema jurídico dado sea un 
sistema "autoritativo" u "oportunista" depende de las actitudes de la gran masa de funcionarios. Si las actitudes relevantes confieren un estatus moral especial a los planificadores, entonces tenemos un "sistema autoritativo". Si, en cambio, los funcionarios piensan que el plan al que están atados es moralmente bueno (independientemente de qué opinión tienen de los autores de ese plan) el sistema es "oportunista".

Adviértase que, dado esto, la empresa en cuestión no es ya de metainterpretación. La metainterpretación exige, inter alia, extraer las actitudes de confianza de los planificadores. Aquí, en cambio, estamos tratando con las actitudes (¿morales?) de los funcionarios. Por lo que únicamente podremos recurrir al método metainterpretativo de los planificadores una vez que hayamos decidido, a través de un procedimiento diferente, que el sistema relevante es un "sistema autoritativo".

Todo esto da lugar, creo, a las preguntas siguientes. ¿Qué nivel de acuerdo ha de verificarse entre los funcionarios, acerca de esta propiedad del sistema, para que se dé un sistema autoritativo? ¿Cómo es posible determinarlo? ¿Es el caso que un sistema de ese tipo alguna vez se da? ¿No es, en cambio, bastante posible que funcionarios diferentes posean ideas muy diferentes (y algunas veces, incluso ninguna idea) acerca de ello? ¿Qué sucede si los funcionarios están divididos entre las dos actitudes a las que me he referido más arriba? ${ }^{56}$ ¿Quiénes son los diseñadores del plan, a quienes se dirige un alto respeto en los "sistema autoritativos" (solo los framers, o también los legisladores y los jueces sucesivos)?

Yo no poseo respuestas precisas a estas preguntas, pero creo que la teoría de los planes debería ofrecerlas. Lamentablemente, los pasajes relevantes de Legalidad son demasiado breves. En lugar de un argumento acerca de (a) el procedimiento para identificar tanto la actitud relevante de los funcionarios, como el nivel de convergencia de acti-

56 La tesis que la unidad del sistema jurídico no es per se derrotada si los funcionarios siguen diferentes reglas de reconocimiento posee efectivamente cierto crédito entre los filósofos del derecho. Véase por ejemplo Raz, J., Razón práctica y normas, op. cit., p. 169-170; Id., La autoridad del derecho, op. cit., p. 126; Kramer, M., "Of Final Things: Morality as one of the Ultimate Determinants of Legal Validity", en Where Law and Morality Meet, Oxford, Oxford U. P., 2004. 
“¿Cuál es el plan?”. Sobre la interpretación y la metainterpretación...

tudes que es necesario para que se dé el tipo de sistema relevante; y en lugar de un argumento acerca de (b) la descripción de la situación actual de un sistema jurídico dado (tal como el de los Estados Unidos) respecto de las actitudes efectivas de los funcionarios (tribunales, legislaturas, etc.); Shapiro nos proporciona únicamente algunos breves comentarios dispersos, y una cita de un artículo periodístico ${ }^{57}$, sin ofrecer ninguna evidencia adicional en favor de su tesis (crucial).

Por mi parte, señalaré solo un par de intuiciones, vagamente formuladas. Primero, responder a algunas de las preguntas exigiría, de nuevo, una investigación que conlleva considerar argumentos y razones sustantivas, intenciones, actitudes proposicionales, ideologías. En breve, exige, de nuevo, una investigación evaluativa sustancial, y no una meramente empírica.

Segundo, si, tal como sospecho, en los sistemas jurídicos contemporáneos, caracterizados por su complejidad y por la multiplicidad de actores (por oposición a los sistemas "carismáticos", tal como Max Weber los denominara), no es nunca el caso (o lo es solo raramente) que la masa de funcionarios jurídicos acepte, o haga como que acepta, las reglas del sistema, simplemente porque esas reglas han sido creadas por quienes poseen una autoridad o juicio moral superior; entonces toda la maquinaria metainterpretativa desarrollada por Shapiro posee en realidad un alcance bastante restringido. Parecería que la mayoría de, si no todos, los sistemas jurídicos contemporáneos exigiría una teoría metainterpretativa diferente y no la avanzada por la teoría de los planes.

\section{IV. ¿Quiénes son los planificadores?}

Las dudas que he intentado presentar en la sección precedente se encuentran seguramente emparentadas con una única duda mayor, que en realidad ha ya aparecido en distintos lugares de mi trabajo. Esta duda se relaciona con la dificultad para identificar, en el argumento de Shapiro, quiénes son exactamente los planificadores de un sistema jurídico.

57 Shapiro, S., op. cit., pp. 351-352. 
Creo que Shapiro no ha hecho mucho para aclarar cierta ambigüedad en este punto. En muchos pasajes del libro deja en claro (en cuanto se refiere al sistema jurídico estadounidense) que tiene en mente a los Framers, incluyendo también a los ratificadores y a los autores de las enmiendas. Es decir, tiene en mente a quienes originalmente diseñaron el sistema (de hecho, parte de la refutación de los argumentos de Dworkin se apoya en una digresión histórica, bien rica e interesante, acerca de las actitudes de confianza de los Framers ${ }^{58}$. En otros pasajes, en cambio, Shapiro incluye en la categoría de los planificadores también a otros funcionarios que pueden afectar, y de hecho afectan, el plan original -claramente los legisladores más recientes ${ }^{59}$. Esta afirmación es ciertamente razonable, pero podríamos preguntarnos si es consistente con la definición de "un sistema autoritativo" sobre la que se apoya gran parte de los argumentos metainterpretativos de Shapiro. Asimismo, en otros pasajes, Shapiro incluso afirma que la distribución de la discreción interpretativa entre los funcionarios (que es uno de los rasgos fundamentales del diseño del plan maestro) es un trabajo exclusivo de los legisladores ${ }^{60}$, quienes por lo tanto terminan también siendo "diseñadores del plan".

Para aclarar mi argumento es útil señalar que la teoría de los planes está basada en (inter alia) dos ideas que al final parecen difíciles de reconciliar, a saber, (a) la idea según la cual la lógica de la planificación exige que el contenido del plan sea determinable sin recurrir al mismo

58 Shapiro dedica bastante atención (en el capítulo XI y en varios pasajes más de su libro) a los puntos de vista de los Framers (op. cit., p. 441: "los diseñadores de la temprana república norteamericana").

59 Ibidem, p. 430: "los diseñadores del sistema norteamericano actual incluyen no solo a los constituyentes y ratificadores de la Constitución de 1878, sino a los numerosos agentes que han cambiado el aspecto del sistema durante los últimos doscientos años. Los constituyentes y ratificadores de la Decimocuarta Enmienda son tanto los diseñadores del régimen actual como los constituyentes y ratificadores de la Constitución original. En la medida en que el meta-intérprete se centre en el sistema actual, el conjunto relevante de planificadores para la meta-interpretación es el actual, a saber, aquellos cuya planificación todavía no ha sido modificada o extinguida por planificadores subsecuentes". 
“¿Cuál es el plan?”. Sobre la interpretación y la metainterpretación...

tipo de argumentos que el plan está destinado a resolver ${ }^{61}$, y (b) la idea que los planes pueden ser incompletos, y que pueden ser diseñados de manera "incremental".

Supongamos que, en el derecho, un juez descubre que para determinado tipo de casos el plan "se agota". Esta situación es casi inevitable puesto que, según la teoría de los planes, el derecho posee límites ${ }^{62}$ (en sintonía con el positivismo excluyente). Y supongamos que en ese tipo de casos el juez decide de todos modos resolver el caso, "agregando" algo al plan origina $1^{63}$. Esto claramente conlleva recurrir al mismo tipo de argumentos controvertidos que el plan estaba destinado a resolver. Ahora bien, ¿cómo deberíamos describir esta situación? Según la idea (a) apenas mencionada, el plan ciertamente no ha funcionado ${ }^{64}$, y el juez, en cierto sentido, ha escrito un nuevo plan ${ }^{65}$. Por el otro lado, siguiendo la idea (b) mencionada más arriba, el juez ha simplemente

61 Ibidem, p. 226: "Los planes pueden reemplazar nuestro razonamiento solo si podemos descubrir su existencia y contenido sin deliberar sobre sus méritos". A partir de esto, se seguirían tanto SLOP como LOGEP.

62 Ibidem, p. 339: "cuando las normas con pedigrí se agotan (lo que tiene que ocurrir, dado el argumento sobre los límites de los social [sic]), la planificación social que el derecho proporciona también se agota".

63 La indeterminación, según Shapiro, "es un rasgo y no un problema. Incluso si se pudieran elaborar reglas perfectamente precisas, estas serían necesariamente arbitrarias y probablemente generarían caos. En muchos casos es mejor dejar que otros completen los detalles cuando están en una mejor posición para juzgar qué curso de acción es preferible" (ibidem, p. 317).

64 Ibidem, p. 316: "en numerosas instancias, la mejor explicación de por qué los abogados no conocen el derecho es que no existe derecho que conocer. Pueden descubrir, por ejemplo, que su caso se encuadra en la zona de penumbra de la regla. $\mathrm{O}$ una ley puede disponer una cosa, mientras que otra ley prevé algo distinto. Entonces, la incertidumbre sobre cómo proceder en esos casos no reflejará su desconocimiento del derecho, sino que será un reflejo de sus dudas sobre cómo debe desarrollarse el derecho o de qué modo se pronunciará eventualmente un tribunal" (cursivas agregadas).

65 Según la teoría de los planes, esto debería entenderse como "una obligación de emprender una nueva planificación social. Así, considera que las normas que carecen de pedigrí que aplican eventualmente generan nuevos planes/norma, no que son el descubrimiento de planes/normas ya existentes. Porque si los planes/normas existentes pudieran ser descubiertos solo a partir del razonamiento moral, sería de entrada absurdo tenerlos" (ibidem, p. 339, cursivas agregadas). 
Giorgio Pino

"agregado" algo al mismo plan original, se trata de un desarrollo incremental del mismo plan.

Así, la teoría de los planes involucra dos ideas que, si bien por separado parecen plausibles, son evidentemente irreconciliables. Primero, la idea que los planes desempeñan su papel específico cuando eliminan los costos de deliberación del proceso de toma de decisiones en contextos de incertidumbre, de controversia moral, etc. (que, a su vez, requiere que el plan pueda ser interpretado, y deba ser interpretado, de una manera no-evaluativa). Segundo, la idea que una planificación total sería en realidad un pesadilla, aun cuando fuera posible. Es posible desarrollar los planes de manera incremental, y forma parte de la estructura normal de los planes (incluyendo los planes jurídicos) el dejar lugar a áreas de indeterminación.

La única posibilidad para lidiar con estas dos afirmaciones en conflicto es, creo, "enrolar" también a los jueces entre los diseñadores del plan, contrariamente a la estructura del argumento de Shapiro (al menos, tal como yo lo leo) que parece reservar el título honorífico de "planificadores" a los funcionarios de alto rango que tienen a su cargo la estructuración del plan: los Framers en primer lugar y, quizás, también los legisladores ("diseñadores del sistema") ${ }^{66}$.

Ahora bien, ¿cuáles serían las implicaciones de enrolar también a los jueces en la categoría de planificadores ${ }^{67}$ Pienso que la principal implicación es que también los planes producidos por la judicatura, las "doctrinas" elaboradas por los tribunales, dan forma al plan legal en su totalidad. El plan legal es (también) lo que las cortes dicen que es, y también esto ha de ser tenido en cuenta en la etapa de "extracción" de la metainterpretación (que a su vez se vuelve quizás mucho más compleja e incluso menos "empírica" que lo que considera Shapiro).

Esto va de la mano con otro punto similar. En diferentes partes de su argumento, Shapiro se refiere a los "diseñadores del sistema" como

66 Véase ibidem, pp. 419-423.

67 En un sentido obvio y débil, los jueces son siempre planificadores. Puesto que una norma jurídica es un plan y una decisión judicial es una norma (individual), los jueces planifican cada vez que resuelven un caso. 
“¿Cuál es el plan?”. Sobre la interpretación y la metainterpretación...

si se tratara de un círculo cerrado, un hortus conclusus. Me pregunto si esto es una percepción correcta del derecho, especialmente cuando se trata de los sistemas jurídicos contemporáneos de alta complejidad, donde las relaciones de poder entre los diferentes actores son constantemente objeto de negociación. El campo de batalla suele denominarse, claro está, "interpretación jurídica".

En los sistemas jurídicos contemporáneos, varios actores diferentes dan forma al derecho, y muchos actores dan forma o reforman sus propios poderes de toma de decisión -y los de los demás también-. En los Estados Unidos, después de todo, el poder de la Corte Suprema para revisar la legislación ha sido establecido por la Corte Suprema misma (Marbury v. Madison). La Corte Constitucional italiana y las de muchos países europeos han reiteradamente ampliado ellas mismas sus poderes, por ejemplo, afirmando que determinados principios constitucionales son inmunes a reforma constitucional (y, por lo tanto, que una reforma constitucional puede estar sujeta a revisión judicial de constitucionalidad). El proceso de integración de los sistemas jurídicos europeos, hacia un sistema jurídico europeo único, ha sido en gran parte llevado a cabo por los tribunales (tanto Cortes Supremas nacionales como la CEJ).

Por lo tanto, la idea que un sistema jurídico es el producto de un número fijo y cerrado de diseñadores de planes parece un tanto simplista $^{68}$. Los sistemas jurídicos evolucionan, y su evolución estructural es, no solo, y no siempre, una cuestión de planificación de arriba hacia abajo por parte de los legisladores. La evolución de los sistemas jurídicos es a veces también consecuencia de las decisiones judiciales. Los jueces no solo son aplicadores de planes, sino que a veces son también, y de manera sustancial, diseñadores.

68 En el cuadro que he diseñado, todos los actores que mencioné deberían concebirse como recurriendo regularmente al enfoque metainterpretativo del Ojo de Dios. Cada uno de ellos evalúa su propio nivel de confiabilidad y decide en conformidad a él. Shapiro dice que el enfoque del Ojo de Dios "frustra la capacidad del derecho para alcanzar su objetivo fundamental” (ibidem, p. 421). Si ello es así, entonces debería- 
Giorgio Pino

\section{Bibliografía}

Celano, B., "Come deve essere la disciplina costituzionale dei diritti?", en Pozzolo, S. (ed.), La legge e i diritti, Torino, Giappichelli, 2002, p. 89-123.

Celano, B., "Giusnaturalismo, positivismo giuridico e pluralismo etico", Materiali per una storia della cultura giuridica, 2005, p. 161-184.

Chiassoni, P., "Una mirada desde el realismo analítico: vieja metafísica, señorío de las verdades obvias y positivismo sospechoso", Revista Discusiones, XX (2), 2017.

Green, L., "Legal Positivism", en Stanford Encyclopedia of Philosophy, 2003.

Hart, H. L. A. (1961), The Concept of Law, Second Edition, Oxford, Oxford University Press, 1994.

Hart, H. L. A., Post scríptum al concepto de derecho, México, UNAM, 2000, traducción de Rolando Tamayo y Salmorán.Kelsen, H., Teoría pura del derecho, México, UNAM, 1982, trad. de R. Vernengo. Kramer, M., "Of Final Things: Morality as one of the Ultimate Determinants of Legal Validity", en Where Law and Morality Meet, Oxford, Oxford U. P., 2004.

MacCormick, N., Legal Reasoning and Legal Theory, Oxford, Oxford U. P., 1978.

Raz J., Razón práctica y normas, Madrid, Centro de estudios constitucionales, 1991, trad. de J. Ruiz Manero.

Raz, J., La autoridad del derecho. Ensayos sobre derecho y moral, México, UNAM, 1985, trad. de R. Tamayo y Salmorán.

Shapiro, S., "The 'Hart-Dworkin' Debate: A Short Guide for the Perplexed", en Ripstein, A. (ed.), Ronald Dworkin, Cambridge, Cambridge U. P., 2007.

Shapiro, S., Legalidad, Madrid-Barcelona, Marcial Pons, 2014, traducción de Papayannis, D. M. y Ramírez Ludeña, L.

mos concluir que la inmensa mayoría de los sistemas jurídicos contemporáneos son "ejemplos periféricos" de sistemas jurídicos. 
“¿Cuál es el plan?”. Sobre la interpretación y la metainterpretación...

Villa, V., "Legal Theory and Value-Judgements", Law and Philosophy, 16, 1997, pp. 447-477.

Waldron, J., "Do Judges Reason Morally?", en Huscroft, G. (ed.), Expounding the Constitution. Essays in Constitutional Theory, Cambridge, Cambridge U. P., 2008, pp. 38-64. 